Check for updates

Cite this: RSC Adv., 2018, 8, 34793

Received 1st May 2018

Accepted 17th September 2018

DOI: $10.1039 / \mathrm{c} 8 \mathrm{ra03730b}$

rsc.li/rsc-advances

\section{Optimal design of an antireflection coating structure for enhancing the energy-conversion efficiency of a silicon nanostructure solar cell}

\begin{abstract}
Qiaoyun Fan, $\uparrow$ Zhiqiang Wang† and Yanjun Cui (D) *
In this paper, we present our investigation of the optical and electrical characteristics of silicon solar cells using silicon nanowire, silicon nanocone, silicon nanopillar, and silicon nanopillar/silicon nitride structures, which were obtained by the Ag-assisted electroless etching method and ICP etching with extreme ultraviolet lithography. We introduced the formation mechanism for four kinds of solar cells. We simulated the absorption of four structures for different parameters. Furthermore, we also performed current density-voltage $(J-V)$ characterization of the samples with silicon nitride, which exhibited an improvement of the power conversion efficiency (PCE) in contrast to the samples without silicon nitride. It was found that the properties of trapping light for silicon nitride had a prominent impact on the improvement of the PCE in the silicon nanopillar solar cells.
\end{abstract}

\section{Introduction}

For a traditional monocrystalline silicon solar cell, where the broader band gap allows absorbing longer light waves, the thickness of the solar cell is about $500 \mu \mathrm{m},{ }^{1}$ which leads to a high cost for the silicon material. Thinner solar cells have been applied in industry to lower the cost, in which the thickness of the solar cell is about $180 \mu \mathrm{m}$. However, a thinner solar cell normally absorbs less light, meaning it cannot generate as high a PCE. ${ }^{2}$ A radial p-n junction of silicon nanorod (nanowire, nanocone, or nanopillar) arrays has been applied on photovoltaic devices, which is a new technology for reducing the cost and improving the efficiency of silicon solar cells. ${ }^{3-8}$ For the radial $\mathrm{p}^{-}$ $\mathrm{n}$ junction of a solar cell, orthogonalization is generated between the light absorption and carrier transport direction. Photons are absorbed along the axial direction of a silicon nanopillar solar cell as well as carriers are generated along the radial direction of the silicon nanopillar solar cell. ${ }^{9-11}$ Although a low quality of silicon material has been applied in silicon nanorods, the separation and transmission of carriers are also accomplished by the radial junction of the silicon nanorods. This structure has been prepared on the surface of a solar cell, and can decrease the material cost and improve the PCE. ${ }^{\mathbf{1 2 - 1 4}}$

To prepare the silicon nanowire arrays, two method approaches were developed to solve the problem: one is the growth method of "bottom-up,"15-17 the other is the etching method of "top-down."18-20 Also, the metal-assisted chemical etching method, ${ }^{\mathbf{2 1 - 2 3}}$ which has a simple operation and low cost

Institute of Applied Mathematics, Hebei Academy of Sciences, Shijiazhuang 050081, People's Republic of China. E-mail: cuiyanjun_sxs@163.com

$\dagger$ These authors contribute equally. of production, has been applied to prepare silicon nanowires. ${ }^{\mathbf{1 3 2 4 - 2 6}}$ In addition, silicon nanocone and nanopillar arrays in the silicon wafers have been generated by using ICP etching and extreme ultraviolet lithography. ${ }^{10,27-29}$ As one widely-used method for semiconductor processing, the ICP etching method has been applied, with several advantages, including low damage, high etching rates, high anisotropy, and high selection ratio. ${ }^{30}$ The ICP method is a very complex physical and chemistry process, which is composed of two components: one is the interaction between the free radicals, metastable particles, and atoms by the inductively coupled grow discharge of etching gas; the other is the interaction between the active particles and the surface of a sample. ${ }^{31}$ The main physical process is the ion bombardment on the surface, which has an auxiliary function for the chemical reaction rather than just the pure physical process of the sputtering etching. This process is not only applied to generate lattice damage caused by breaking chemical bonds and increasing the adhesive strength of the particles, but also to help power the reaction surface and to remove the volatile residues on the chip. ${ }^{32}$ In experiments, a certain thickness of the pattern on a photoresist is deposited on the silicon wafer by using lithography technology, and then, the ordered nanocone or nanopillar arrays are formed via ICP etching with controlling the procedure's parameters (etching power, temperature, time, pressure, etc.).

Silicon nanowires arrays with the characteristic of light antireflection and light trapping have been applied in a solar cell. ${ }^{33}$ This light characteristic of silicon nanowire arrays was caused by a large surface and the multiple scattering between the nanowires. The average reflection of the silicon nanowire in the range of $300-600 \mathrm{~nm}$ was lower than $2 \% .^{34-36}$ Nanocone arrays with an effective refractive index profile between the air 
and silicon substrate displayed the optimal properties of antireflection, which were similar to multilayer antireflection films. Also, the average reflection in the range of 300-800 $\mathrm{nm}$ was lower than $1 \% .^{\mathbf{4}, 8,37-39}$ Although the reflection of silicon nanopillar arrays is not lower than nanowire or nanocone arrays, the efficiency of cells with a lower defect structure is improved by the increased light absorption with multiple reflections between the nanopillars., ${ }^{\mathbf{5 , 4 0 , 4 1}}$ The three structures with the optimal properties of light trapping significantly improved the path length of incident light. Silicon solar cells based on silicon nanowire, nanocone, and nanopillar arrays have some great advantages and thus promising prospects. They are used not only to prepare cells using lower cost materials but higher lighttrapping properties. Moreover, it can enhance the spectrum of sunlight absorption by regulation of the band gap width of the cells.

In this paper, a novel strategy for preparing ordered and highly consistent nanocone and nanopillar arrays on a silicon planar is reported by using ICP etching and extreme ultraviolet lithography. In the whole etching process, the application of the ICP etching or lithography is important. This method for preparing silicon nanocone or nanopillar arrays has some beneficial characteristics, such as being a low-cost and simple process, and it is also repeatable. Furthermore, we also prepared the nanowire on the silicon surface by a Ag-assisted chemical etching method. Prof. Martin Green's group from the University of New South Wales reported that the efficiency of silicon solar cell could be enhanced by decreasing the recombination of carriers. ${ }^{42}$ Their research showed that the efficiency of cells with a silicon oxide or silicon nitride film deposited on the surface of a $\mathrm{p}-\mathrm{n}$ junction, emitter, or back electrode could be greatly improved. So silicon nitride as an antireflection film was applied on silicon nanopillar solar cells. In addition, we simulated the absorption for three structures of solar cells with different lengths and periodicities. Also, the optimal combined light trapping structure with the antireflection coating of the silicon nanopillar solar cell was also investigated.

\section{Experimental details}

Fig. 1(a-e) illustrates the main experimental steps of the three structures on the silicon surfaces with the Ag-assisted chemical etching method, ICP etching method, and lightography technique. In the experiment, n-type (100) silicon wafers (resistivity $\sim 3 \Omega \mathrm{cm}$ ) were applied for preparing the three structures on the silicon surface. Also, all the silicon wafers were cleaned by RAC 1 and RAC 2 solution, respectively.

\subsection{Method for preparing the silicon nanowires}

(1) The back of silicon wafers were coated with the positive photoresist (KMP-BP212-30) with an approximate thickness of $200 \mathrm{~nm}$ and then the samples were cured at $90{ }^{\circ} \mathrm{C}$ for $20 \mathrm{~min}$ in a convection oven (see Fig. $1\left(b_{1}\right)$ ).

(2) To remove the silicon dioxide, the samples were then etched in $2 \% \mathrm{HF}$ solution for $1.5 \mathrm{~min}$ at room temperature, and then the samples were immediately placed into a solution containing $0.005 \mathrm{M} \mathrm{AgNO}_{3}$ and 9.6 $\mathrm{M} \mathrm{HF}$ and stirred for $3 \mathrm{~min}$. Then, Ag nanoparticles were deposited on the silicon surface (see Fig. 1(c $\left.c_{1}\right)$ ).

(3) To obtain the silicon nanowire structure, the samples were immersed in an etchant composed of 9.6 M HF and $0.6 \mathrm{M}$ $\mathrm{H}_{2} \mathrm{O}_{2}$ for different etching times of 15, 30, 45 and 60 min in the dark at room temperature. Finally, the silicon dioxide and $\mathrm{Ag}$ nanoparticles were dissolved in $2 \% \mathrm{HF}$ solution and dilute nitric acid solution $\left(V_{\mathrm{HNO}_{3}} / V_{\mathrm{H}_{2} \mathrm{O}}=1: 1\right)$ at room temperature, respectively. To remove the positive photoresist of the samples, the wafers were also placed into acetone solution, and largearea and highly consistent and different lengths of nanowire arrays on the silicon wafers were obtained.

\subsection{Method for preparing the silicon nanocones and nanopillars}

(1) To obtain silicon nanocones, the cleaned silicon wafers were also coated with several layers of positive photoresist (KMPBP212-30) with a thickness of about $200 \mathrm{~nm}$ on the surfaces (see Fig. $1\left(b_{2}\right)$ ), while to obtain the silicon nanopillars, a $\mathrm{SiO}_{2}$ buffered layer with dozens of nanometers was deposited on the silicon surface by using PECVD (plasma-enhanced chemical vapor deposition) before the coating of the positive photoresist (see Fig. $1\left(b_{3}\right)$ ).

(2) The samples were cured at $90{ }^{\circ} \mathrm{C}$ for $20 \mathrm{~min}$ in a convection oven, and then the positive photoresist was exposed using an Extreme Ultraviolet Lithography (URE-2000/25) setup. Exposure of the photoresist with a $\left(2.5 \times 2.5 \mathrm{~cm}^{2}\right)$ and $0.5 \mu \mathrm{m}$ triangulation point or $5 \mu \mathrm{m}$ circular pattern of the lithography mask was achieved by $90 \mathrm{~s}$ exposure for the nanocone or nanopillar, respectively. The exposed photoresist was removed by using a developer, leaving triangular-shaped or circularshaped photoresist dots on the sample surface (see Fig. 1(c $c_{2}$ and $\left.c_{3}\right)$ ). The samples were finally cured at $120{ }^{\circ} \mathrm{C}$ for $20 \mathrm{~min}$ in a convection oven.

(3) To prepare the silicon nanopillar array, the exposed silicon dioxide of the samples was etched in a solution of $\mathrm{NH}_{4} \mathrm{~F}$, $\mathrm{HF}$, and deionized water with the ratio $6 \mathrm{~g}: 3 \mathrm{ml}: 10 \mathrm{ml}$ for $45 \mathrm{~s}$ at room temperature (see Fig. $1\left(c_{3}\right)$ ). Then, the ordered nanocone or nanopillar arrays were formed via the ICP etching method (see Fig. $1\left(d_{2}\right.$ and $\left.d_{3}\right)$ ). To remove and leave behind triangular-shaped or circular-shaped photoresist dots, the samples were immersed in acetone solution. The silicon dioxide was removed in $2 \% \mathrm{HF}$ solution for $3 \mathrm{~min}$, to obtained large, ordered, and height consistent nanocone or nanopillar arrays on the silicon wafers (see Fig. $1\left(\mathrm{e}_{2}\right.$ and $\left.\mathrm{e}_{3}\right)$ ).

The three kinds of samples were all diffused at $1000{ }^{\circ} \mathrm{C}$ for 30 min using liquid $\mathrm{BBr}_{3}$ as the boron source. After the removal of borosilicate glass from the upper surface and edge isolation, the electrodes of the front and back sides of three structures were deposited with silver film with an approximate thickness of $500 \mathrm{~nm}$ using a thermal evaporator under a vacuum pressure of $3.5 \times 10^{-5}$ mbar. The silicon nanopillar solar cells were deposited with silicon nitride by PECVD. The detailed procedures for fabricating the three structures are presented in Fig. 1. The surface morphologies of silicon samples were obtained by 


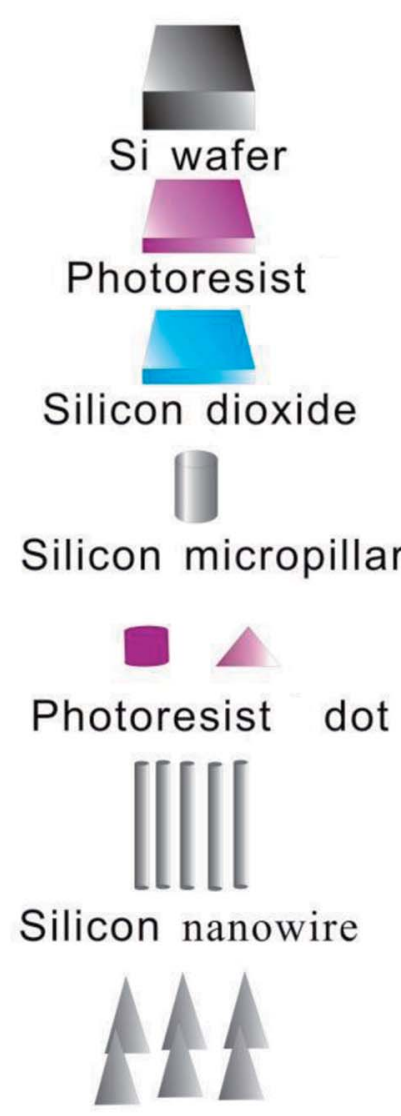

Silicon nanocone
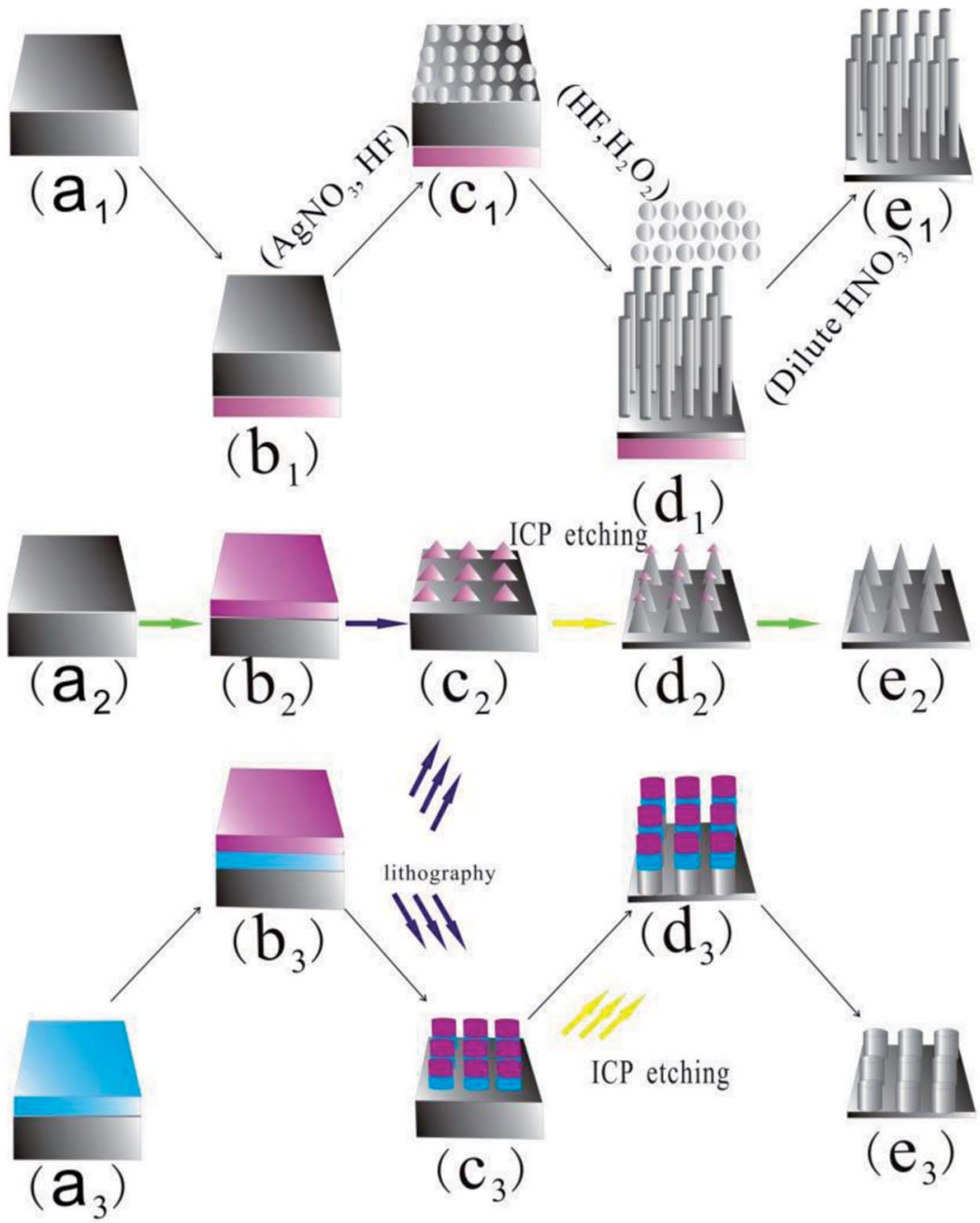

\section{DFlow Diagram of Experiment}

Fig. 1 Schematic diagram showing the process flow in obtaining silicon nanowires, nanocones, nanopillars via the Ag-assisted chemical etching method, ICP etching method, and lithography technique, respectively.

SEM (FEI Quanta 250 FEG). The ICP etching process of the silicon sample was performed using the Sentech Ptsa ICP-RIE Etcher 500. The reflectance spectra of the silicon samples were investigated using a spectrophotometer (UV-1601).

\section{Result and discussion}

First, we examined the light absorption at wavelengths of 300$700 \mathrm{~nm}$ of the silicon solar cell with the three different structures: nanowire, nanocone, and nanopillar arrays, as shown in Fig. 1. By simulations based on a finite element method (FEM), ${ }^{4-48}$ the power flow distribution was simulated by TM illumination and a 2D model using different heights or periodicities of the three kinds of solar cell. The effect of this lighttrapping structure on absorption of the nanopillar structure with the addition of silicon nitride was also investigated, and all the parameters were investigated.
We assume that the thicknesses of $\mathrm{n}$ and the $\mathrm{Al}$ layer for all the structures were $150 \mathrm{~nm}$ and $40 \mathrm{~nm}$, respectively. The effect of incident light perpendicular to the surface of solar cells on the absorption was optimal, so all the simulations based on incident light were vertical. In the simulation, we defined the absorption of incident light for the silicon solar cell as $A(\lambda)$ :

$$
A(\lambda)=\frac{\omega \varepsilon_{0} \int_{V_{1}}^{V_{0}} \operatorname{Im}[\varepsilon(\omega)]|E|^{2} \mathrm{~d} v}{S\left|\operatorname{Re}\left(E_{\mathrm{i}} \times H_{\mathrm{i}}\right)\right|}=\frac{I_{\mathrm{abs}}(\lambda)}{I_{\mathrm{in}}(\lambda)}
$$

where $S$ is the surface area of the integrating region, $\mid \operatorname{Re}\left(E_{\mathrm{i}} \times\right.$ $\left.H_{\mathrm{i}}\right) \mid$ is the average energy density, $\omega$ is the angular frequency of incident light, $\varepsilon_{0}$ is the permittivity of vacuum, $\operatorname{Im}[\varepsilon(\omega)]$ is the imaginary part of the material permittivity, $E$ is the electric field intensity, $V$ is the volume of the calculation area, and $I_{\text {abs }}(\lambda)$ or $I_{\text {in }}(\lambda)$ is the ratio of the power of the absorbed light or the incident light, respectively. The absorption spectrum of the material under AM 1.5 spectrum is 


$$
\delta_{0}(\lambda)=\frac{T(\lambda)}{A(\lambda)}, T(\lambda)=\int_{\mathrm{AM} 1.5 \mathrm{G}\left(\lambda_{\min }\right)}^{\mathrm{AM} 1.5 \mathrm{G}\left(\lambda_{\max }\right)} T(\lambda) \mathrm{d} \lambda
$$

where $\delta_{0}(\lambda)$ is the standard of photon flux density under the AM 1.5 spectrum and $T(\lambda)$ is the total photons of absorption by integral to the whole range of incident light wavelength $\left(\lambda_{\min }\right.$ to $\left.\lambda_{\max }\right)$.

\subsection{Optical characteristics of the four kinds of solar cells}

Fig. 2(a $\left.\mathrm{a}_{1}\right)$ illustrate the absorption spectra of the silicon planar structure with the absorption for different thicknesses or heights ( $L=40,80$, and $120 \mathrm{~nm})$. The film thickness for the $\mathrm{n}$ region and $\mathrm{Al}$ region of the silicon solar cell is the same. As observed in Fig. 2(a $\left(\mathrm{a}_{1}\right)$, the average absorption of $L=120 \mathrm{~nm}$ with the wavelength range of $300-700 \mathrm{~nm}$ based on a planar $\mathrm{Si}$ cell was $17.98 \%$, while the average absorptions of $L=80 \mathrm{~nm}$ and $L=40 \mathrm{~nm}$ were 17.5 and $14.45 \%$, respectively. As can be seen, the light absorption of $L=40$ or $L=80 \mathrm{~nm}$ is less than the light absorption for $L=120 \mathrm{~nm}$ in the three light absorption layer thickness. Fig. 2( $\left.\mathrm{a}_{2}\right)$ illustrates the absorption spectra of silicon wires/nanocones/pillars with the absorption for the same thickness or height $(L=120 \mathrm{~nm})$. The periodicity $(P=10 \mathrm{~nm})$ of the silicon solar cell was the same. As observed in Fig. $2\left(\mathrm{a}_{2}\right)$, the average absorptions of the silicon nanowire solar cell with the wavelength range of $300-700 \mathrm{~nm}$ based on a planar Si cell was $27.95 \%$, while the average absorptions of silicon nanocone and nanopillar solar cells were 36.86 and $24.98 \%$, respectively. As can be seen, the light absorption of silicon nanowire and nanopillar solar cells is less than for the silicon nanocone solar cell with the same layer thickness, albeit the light absorptions for the three kinds of silicon solar cells are more than for the silicon planar solar cell for $L=120 \mathrm{~nm}$. Fig. $2\left(\mathrm{a}_{3}-\mathrm{a}_{6}\right)$ present the distribution of electric field intensity for the four structures $(L=$ $120 \mathrm{~nm}$ ), and also the incident wavelength $\lambda=700 \mathrm{~nm}$. Compared to the planar structure, the distribution of electric field intensity with the incident wavelength $\lambda=700 \mathrm{~nm}$ of the silicon wires/nanocones/pillars solar cells absorbed markedly higher amounts of incident light, which could mainly be attributed to the optimal light trapping at the front sides of such nanostructures.

\subsection{Optical characteristics of the silicon nanowire solar cell}

In this simulation, we defined the diameter of all the models for the silicon nanowire solar cells as $17 \mathrm{~nm}$, and the film thickness of the $\mathrm{n}$ region and $\mathrm{Al}$ region using in silicon solar cells were the same. Fig. 3(b) illustrates the absorption spectra of the silicon
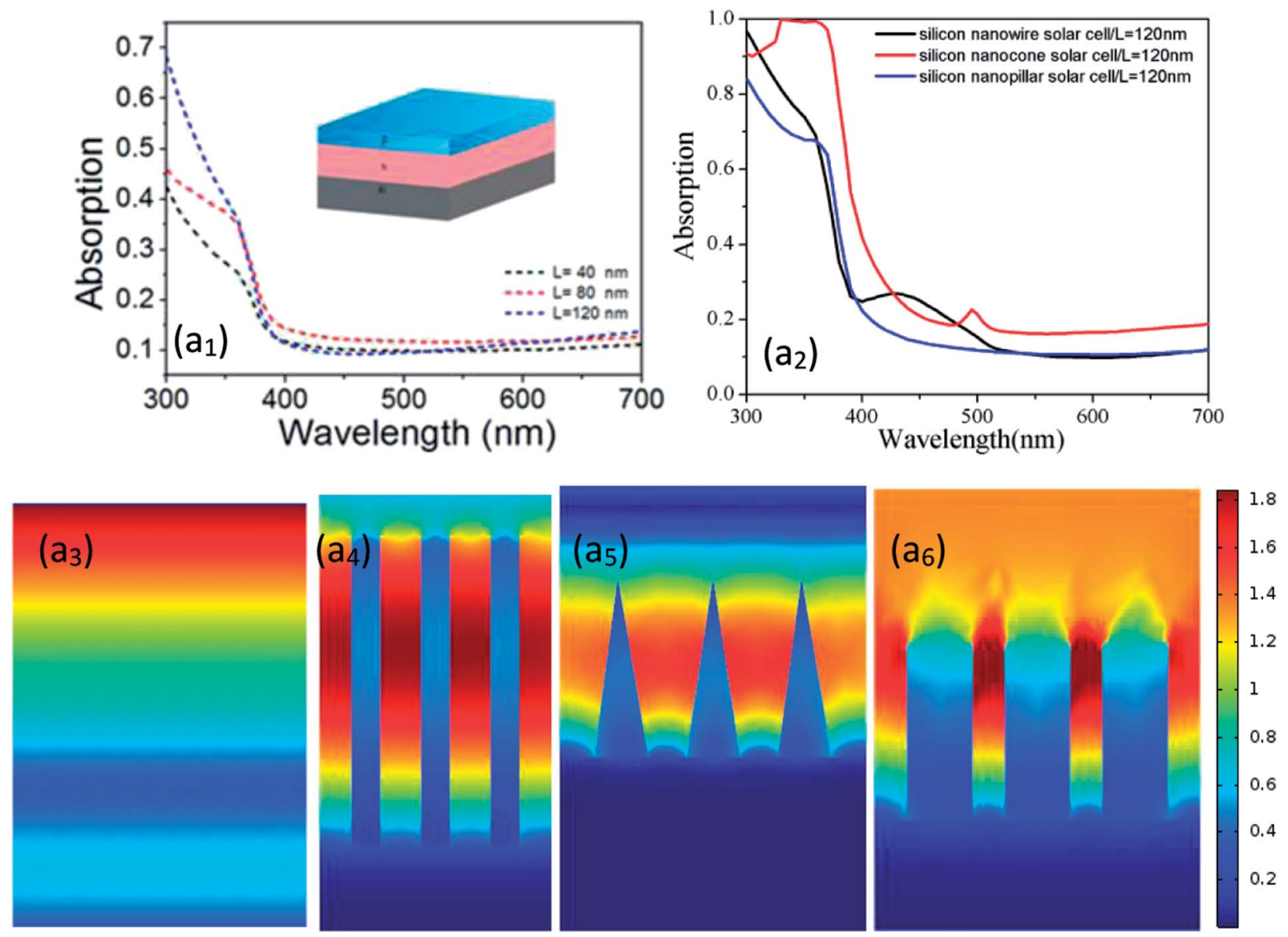

Fig. $2\left(\mathrm{a}_{1}\right)$ Diagram of absorption with the wavelength range of $300-700 \mathrm{~nm}$ based on different heights of the silicon planar solar cell $(L=40,80$, and $120 \mathrm{~nm}) ;\left(a_{2}\right)$ absorption for the three kinds of the solar cells $(L=120 \mathrm{~nm}):\left(a_{3}\right)-\left(a_{6}\right)$ distribution of the electric field intensity for the four kinds of structures $(L=120 \mathrm{~nm})$ illustrated with the incident wavelength $(\lambda=700 \mathrm{~nm})$. 

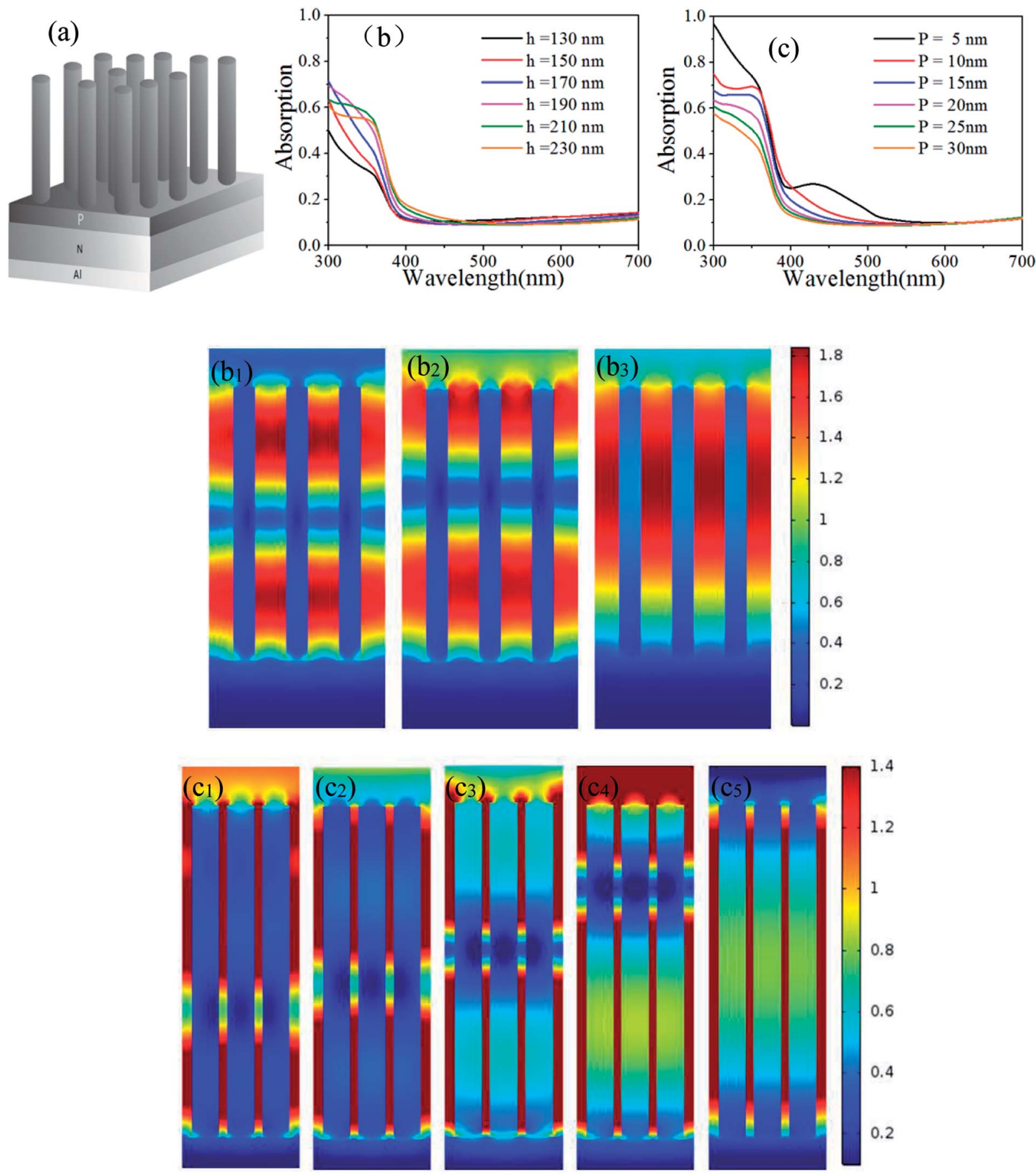

Fig. 3 (a) Diagram of a silicon nanowire solar cell; (b) and (c) absorption with the wavelength range of 300-700 nm based on different heights or periodicities for the silicon nanowire solar cell. The distribution of electric field intensity for this structure $(h=210 \mathrm{~nm})$ is also illustrated in $\left(b_{1}\right)$, $\left(b_{2}\right)$, and $\left(b_{3}\right)$ with the incident wavelength $\lambda=300,500$, and $700 \mathrm{~nm}$, respectively. The distribution of electric field intensity for this structure $(P=$ $5 \mathrm{~nm})$ is illustrated in $\left(c_{1}\right)-\left(c_{5}\right)$ with the incident wavelength $\lambda=300,350,400,500$, and $700 \mathrm{~nm}$.

nanowire solar cell with the absorption for different heights $(h$ $=130,150,170,190,210$ and $230 \mathrm{~nm}$ ) of nanowire arrays. The periodicity of the nanowire arrays was $20 \mathrm{~nm}$. As observed in Fig. 3(b), in this structure, the average absorption with $h=$ $210 \mathrm{~nm}$ with the wavelength range of 300-700 $\mathrm{nm}$ based on the silicon nanowire cell was $20.03 \%$, while the average absorption for $h=130,150,170$ and $190 \mathrm{~nm}$ were $16.63 \%, 17.57 \%, 18.68 \%$, and $19.75 \%$, and the average absorption for $h=230 \mathrm{~nm}$ was $19.72 \%$, respectively. As can be seen, the light absorption for $h$ $=130,150,170,190$ or $230 \mathrm{~nm}$ was less than that of light for $h=$ $210 \mathrm{~nm}$ in this light absorption layer structure. To obtain the optimal light trapping structure for the silicon nanowire solar cell, we investigated the effect of periodicity for the nanowire arrays on the absorption efficiency. The height of the nanowire 
arrays was $210 \mathrm{~nm}$. Fig. 3(c) illustrates the absorption spectra of the silicon nanowire solar cell with the absorption for different periodicities $(P=5,10,15,20,25$, and $30 \mathrm{~nm})$ of the nanowire arrays. As observed in Fig. 3(c), the average absorption for $P=$ $5 \mathrm{~nm}$ with the wavelength range of $300-700 \mathrm{~nm}$ based on the silicon nanowire cell was $27.95 \%$, while the average absorption for $P=10,15,20,25$, and $30 \mathrm{~nm}$ ) were $24.0 \%, 21.97 \%, 20.03 \%$, $18.67 \%$, and $17.59 \%$, respectively. As respected, the light absorption for $P=10,15,20,25$, or $30 \mathrm{~nm}$ was less than that of light for $P=5 \mathrm{~nm}$ in this light absorption layer structure. As a result, to absorb the incident light, with the increase in the nanowire height, the absorption efficiency first increases and then decreases. The maximum average absorption of the nanowire solar cell was $20.03 \%$, and the height and periodicity were 210 and $20 \mathrm{~nm}$. Fig. $3\left(\mathrm{~b}_{1}-\mathrm{b}_{3}\right)$ present the distribution of the electric field intensity for this structure with $(h=210 \mathrm{~nm}$ illustrated with the incident wavelengths of $\lambda=300,500$, and $700 \mathrm{~nm}$, respectively. As shown in Fig. $3\left(b_{1}-b_{3}\right)$, the effect of light trapping for the cells with long incident wavelength is much less rather than for the short incident wavelength. Furthermore, we also discuss the effect of the periodicity of nanowire arrays on absorption efficiency. Fig. $3\left(c_{1}-c_{5}\right)$ present the distribution of electric field intensity $(P=5 \mathrm{~nm})$ with the incident wavelengths of $\lambda=300,350,400,500$, and $700 \mathrm{~nm}$, respectively. The maximum average absorption of the nanowire solar cell was $24.02 \%$ with the more closed nanowire arrays. The effect of the distribution of the electric field intensity was apparently less with the increased light wavelength. Although the absorption peak changed the response to $435 \mathrm{~nm}$, the absorptive intensity was much less than for the shorter wavelength of 300 or $350 \mathrm{~nm}$. Finally, the optimal light trapping for the silicon nanowire solar cell was calculated, and the height, periodicity, and diameter were 210,5 , and $17 \mathrm{~nm}$, respectively. The nanowire solar cell had the maximum average absorption, where $73.9 \%$ of photons were absorbed with the incident light wavelength of $350 \mathrm{~nm}$.

Panels (a-c) of Fig. 4 show SEM micrographs of the silicon nanowire arrays with different etching times $(30,45$, and 60 min). As can be seen in Fig. 4(a-c), the surface on the SEM pictures with the scale of 3 or $10 \mu \mathrm{m}$ has been changed much more than that scaled at $100 \mu \mathrm{m}$. The holes of the silicon nanowire surface gradually become bigger with the increased etching time. This is because the lateral etching process has been increased gradually by the $0.6 \mathrm{M} \mathrm{HF}$ solution with the longer of etching time. The cross-sectional SEM images in Fig. $4\left(a_{1}-c_{1}\right)$ show the lengths of three of the etched samples. As a result, when etching the silicon nanowire, with the increase in etching time, the nanowire length increases and finer nanowire arrays are obtained.

Fig. 4(d) presents the total reflections of silicon nanowire solar cells with different lengths of nanowire arrays. The average reflection of the etching time $(30 \mathrm{~min})$ for the nanowire cell in the range of $300-1100 \mathrm{~nm}$ was $0.085 \%$, and the average reflections of the etching times 15,45 , and 60 min were $0.258,0.099$ and 0.117 . The etching time $30 \mathrm{~min}$ of the silicon nanowire solar cell with the lower reflectance would trap more incident light. This is also because the lateral etching process has been increased gradually with the longer etching time. The bigger the holes are, the higher the average reflection is. In our simulations, we defined the diameter of all the models for the silicon nanowire solar cells to always be $17 \mathrm{~nm}$, but in the experiments, the diameter of the nanowire arrays was gradually reduced. So some errors existed for analyzing the light-trapping of the silicon solar cell between the results of the simulations and experiments.

\subsection{Optical characteristics of the silicon nanocone solar cell}

In our simulations, we defined the diameter of all models for the silicon nanocone solar cells as $80 \mathrm{~nm}$, and the film thickness of the $\mathrm{n}$ region and $\mathrm{Al}$ region used in the silicon solar cells were the same. Fig. 5(b) illustrates the absorption spectra of the silicon nanocone solar cell with the absorption for different heights $(h=70,100,130,160,190$, and $220 \mathrm{~nm}$ ) of nanocone arrays. The periodicity of the nanowire arrays was $50 \mathrm{~nm}$. As observed in Fig. 5(b), in this structure, the average absorption for $h=220 \mathrm{~nm}$ with the wavelength range of 300-700 $\mathrm{nm}$ based on the silicon nanocone cell was $37.63 \%$, while the average absorptions for $h=70,100,130,160,190 \mathrm{~nm}$ were $29.94 \%$, $33.69 \%, 35.21 \%, 35.85 \%$, and $36.63 \%$, respectively. As can be seen, the light absorption for $h=70,100,130,160,190 \mathrm{~nm}$ was less than that of light for $h=220 \mathrm{~nm}$ in this light absorption structure. To obtain the optimal light trapping structure for the silicon nanocone solar cell, we investigated the effect of periodicity for the nanocone arrays on the absorption efficiency. The optimum height of the nanowire arrays was $220 \mathrm{~nm}$. Fig. 5(c) illustrates the absorption spectra of the silicon nanocone solar cell with the absorption for different periodicities ( $P$ $=10,20,30,40,50,60,70$, and $80 \mathrm{~nm}$ ) of nanocone arrays. As observed in Fig. 4(c), the average absorption for $P=60 \mathrm{~nm}$ with the wavelength range of 300-700 $\mathrm{nm}$ based on the silicon nanocone cell was $42.49 \%$, while the average absorptions for $P$ $=10,20,30,40,50,70$, and $80 \mathrm{~nm}$ were $36.86 \%, 37.74 \%$, $37.78 \%, 37.97 \%, 37.62 \%, 36.85 \%$, and $38.29 \%$, respectively. By comparison, the light absorptions for $P=10,20,30,40,50,70$, and $80 \mathrm{~nm}$ were less than that of light for $P=60 \mathrm{~nm}$ in this light absorption structure.

As a result, to absorb the incident light, with the increase in nanocone height, the absorption efficiency is always increased. The maximum average absorption of the nanocone solar cell was $37.63 \%$, and the height and periodicity were $220 \mathrm{~nm}$ and $50 \mathrm{~nm}$. Fig. $5\left(b_{1}-b_{5}\right)$ present the distribution of electric field intensity for this structure $(h=220 \mathrm{~nm})$ illustrated with the incident wavelengths of $\lambda=300,350,380,500$ and $700 \mathrm{~nm}$, respectively.

As shown in Fig. $5\left(b_{1}-b_{5}\right)$, the effect of light trapping for the cells with the incident wavelength from 300 to $380 \mathrm{~nm}$ is increased, while that for the incident wavelength from 380 to $700 \mathrm{~nm}$ is decreased. The peak absorption of the nanocone solar cell with the increasing nanocone height from 70 to $220 \mathrm{~nm}$ is changed with a red-shift in the range of incident light wavelength from 500 to $600 \mathrm{~nm}$. Furthermore, we also investigated the effect of the periodicity of the nanocone arrays on the absorption efficiency. Fig. $5\left(c_{1}-c_{5}\right)$ present the distribution of 

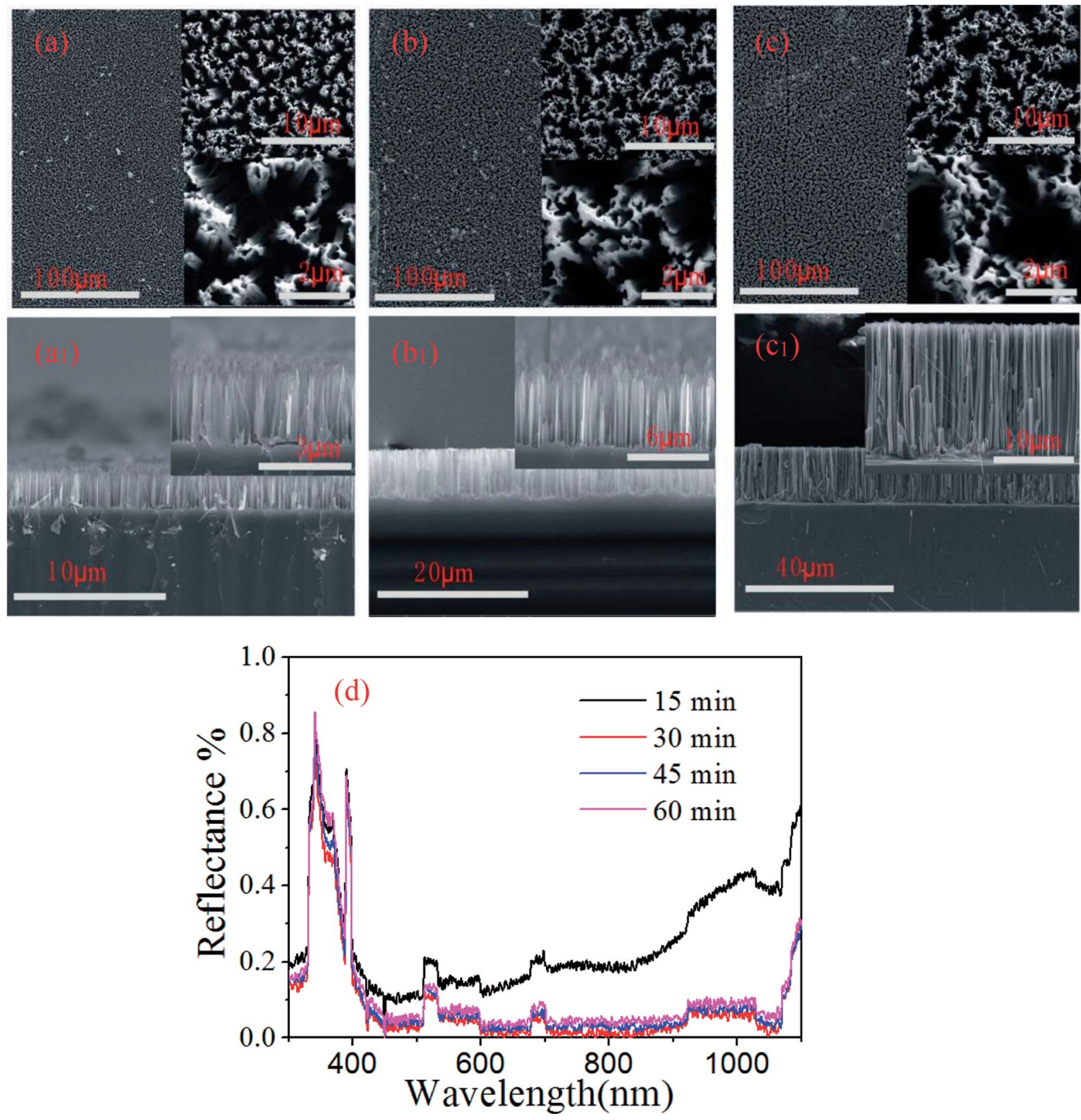

Fig. 4 (a)-(c) SEM micrographs of silicon nanowire arrays with different etching times (30 min, 45 min and 60 min). (a1-c1) Cross-sectional SEM images of three samples. (d) Total reflections of the different etching times for the silicon nanowire solar cells.

electric field intensity $(P=60 \mathrm{~nm})$ with the incident wavelengths of $\lambda=300,415,425,440$, and $700 \mathrm{~nm}$, respectively. The maximum average absorption of the nanocone solar cell was $42.49 \%$ with the more sparse nanocone arrays $(P=60 \mathrm{~nm})$. The peak absorption of the silicon nanocone solar cell is changed with a red-shift in the flowing situations: (1) when the periodicity of the nanocone arrays goes from 10 to $50 \mathrm{~nm}$, and the incident light wavelength is from 500 to $600 \mathrm{~nm}$; (2) when the periodicity of the nanocone arrays goes from 50 to $80 \mathrm{~nm}$, and the incident light wavelength is from 400 to $500 \mathrm{~nm}$. So the peak absorption for the distribution of electric field intensity is gradually less with the increasing periodicity of the nanocone arrays. The effect of the distribution of the electric field intensity with a bigger periodicity has a change response to the shorter incident light wavelength, while a smaller periodicity has a change response to the longer incident light wavelength. Finally, the optimal light trapping for the silicon nanocone solar cell was calculated, and the height, periodicity, and diameter were 220,60 , and $80 \mathrm{~nm}$, respectively. The silicon nanocone solar cell had the maximum average absorption, with $98.46 \%$ of photons absorbed, with an incident light wavelength of $350 \mathrm{~nm}$.

In the ICP etching process, the use of the etching gas of $\mathrm{SF}_{6}$ with a high etching rate will produce free radicals of $\mathrm{F}^{-}$more than $\mathrm{CF}_{4}$ or $\mathrm{CHF}_{3}$. The equation of ionization is:

$$
e+\mathrm{SF}_{6} \rightarrow \mathrm{SF}_{6-n}+n \mathrm{~F}^{*}+e(n=1,2,3,4,5)
$$


(a)

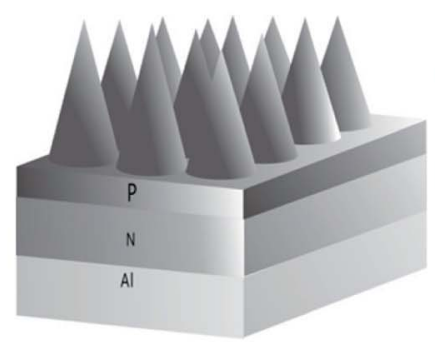

(b)

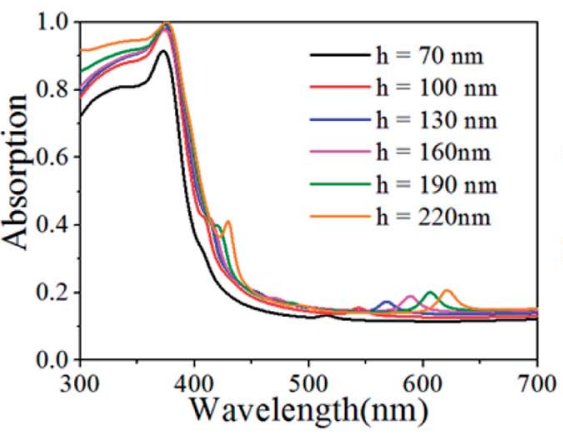

(c)

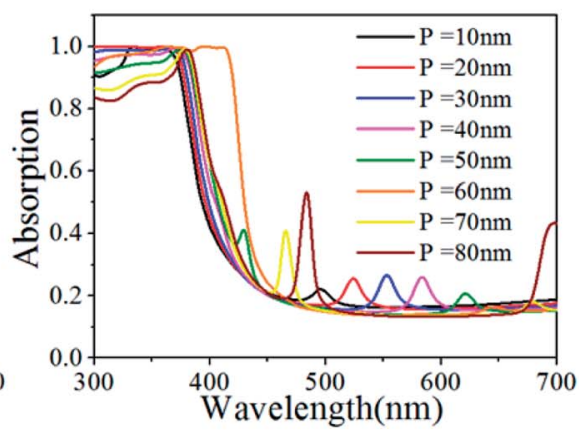

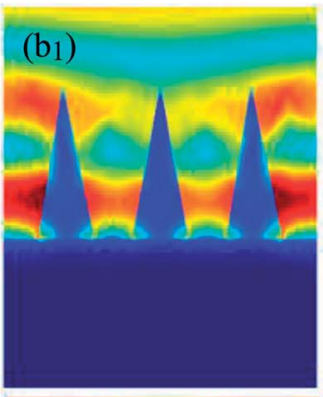
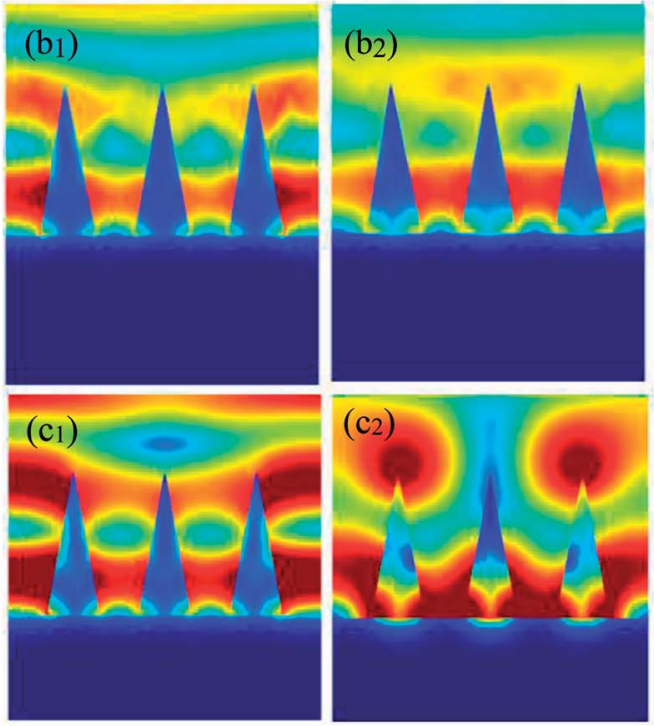
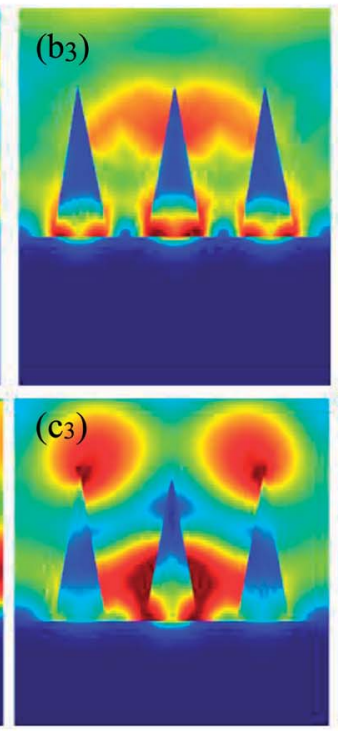
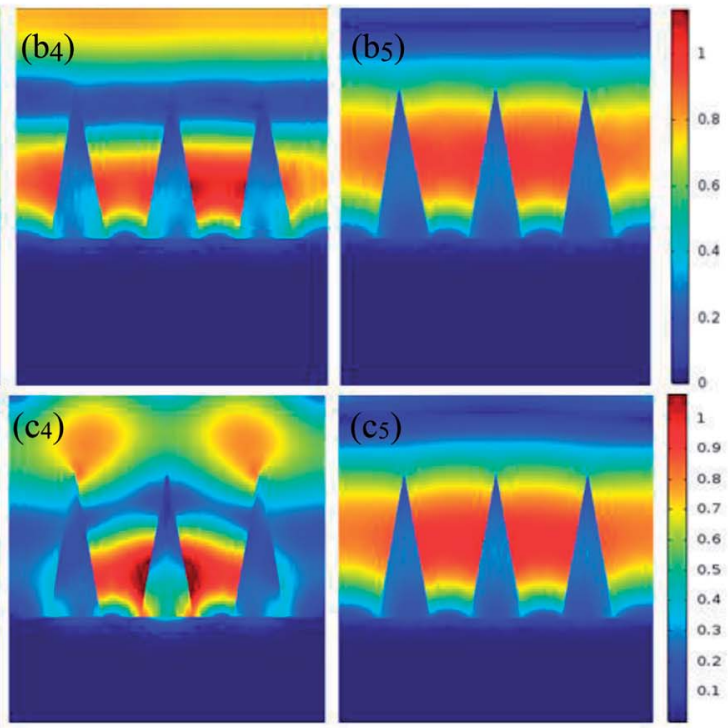

Fig. 5 (a) Diagram of the silicon nanocone solar cell; (b) and (c) absorption with the wavelength range of 300-700 $\mathrm{nm}$ based on different heights or periodicities for the silicon nanocone solar cell. The distribution of electric field intensity for this structure $(h=220 \mathrm{~nm})$ is also illustrated in $\left(b_{1}-\right.$ $\left.b_{5}\right)$ with the incident wavelength $\lambda=300,350,380,500$, and $700 \mathrm{~nm}$, respectively. The distribution of electric field intensity for this structure $(P=$ $60 \mathrm{~nm})$ is illustrated in $\left(c_{1}-c_{5}\right)$ with the incident wavelength $\lambda=300,415,425,440$ and $700 \mathrm{~nm}$.

When the free radicals of $\mathrm{F}^{-}$come close to the silicon surface, they will react with silicon atoms:

$$
\mathrm{Si}+4 \mathrm{~F}^{*} \rightarrow \mathrm{SiF}_{4} \uparrow
$$

The effect of etching can be enhanced with the $\mathrm{SF}_{6}$ etching gas by adding oxygen in to the etching process, because $\mathrm{SF}_{6}$ will break down into various forms of free radicals by the action of the glow discharge. Also, the free radicals from the etching gas can easily form stable fluorides without the oxygen. The free radicals are produced with the adding of oxygen, and then the more and more free radicals produced will react with the silicon atoms. In addition, $\mathrm{SF}_{6}$ is an electronegative gas, so lots of electrons are lost, and the electron density is decreased. The extra electrons have been proved with the adding of oxygen, and are useful to plasma discharge. So, to etch the silicon, the etching gas $\mathrm{SF}_{6}$ is usually used with added oxygen in the etching process.
Panels (a-c) of Fig. 6 show SEM micrographs of the silicon nanocone arrays with different etching times (3 min, $2.5 \mathrm{~min}$ ). As can be seen in Fig. 6(b and c), the surface or cross-sectional SEM images with the scale of 5 or $2 \mu \mathrm{m}$, the cross-sectional SEM image of the nanocone arrays with an etching time of $3 \mathrm{~min}$ is better than that with an etching time of $2.5 \mathrm{~min}$. That is because the edge of the $0.5 \mu \mathrm{m}$ triangulation positive photoresist point is etched by the plasma of $\mathrm{SF}_{6}$ and $\mathrm{O}_{2}$ with the increasing etching time. Then, the exposed silicon is etched. The experimental results showed that the morphologies of the silicon nanocone arrays were deposited on the silicon surface when the triangulation positive photoresist points were changed into the smallest dots by the ICP method. Also, a better shape of the nanocone arrays was achieved at an etching time of $3 \mathrm{~min}$. Fig. 6(d) presents the total reflections of silicon nanocone solar cells with different etching times of nanocone arrays. The average reflection of the etching time (4 $\mathrm{min}$ ) for the nanowire cell in the range of $300-1100 \mathrm{~nm}$ was $0.91 \%$, and the average reflections for etching times of $1.5,2.5$ and 3 min were $3.95 \%$, $2.66 \%$, and $1.86 \%$. The etching time $4 \mathrm{~min}$ of the silicon 

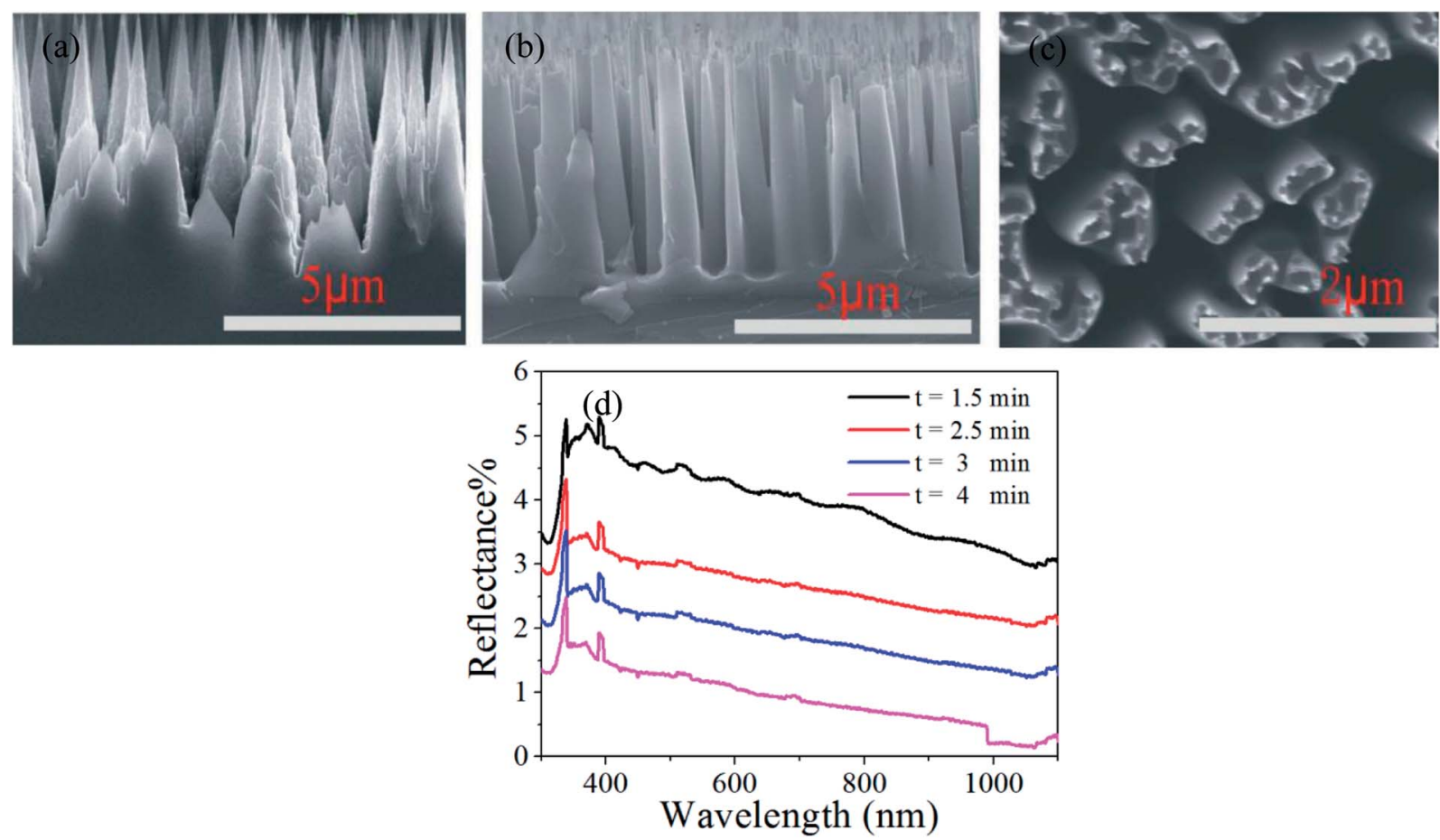

Fig. 6 (a) SEM micrographs of silicon nanocone arrays with the etching time of 3 min. (b) and (c) SEM micrographs of silicon nanocone arrays with the etching time of $2.5 \mathrm{~min}$. (d) Total reflections of the different etching times for the silicon nanocone solar cells.

nanocone solar cell with a lower reflectance would trap more incident light. This is also because the ICP etching process is increased gradually with the longer etching time.

\subsection{Optical characteristics of the silicon micropillar solar cell}

In this simulation, we defined the diameter of all the models for the silicon nanopillar solar cells as $40 \mathrm{~nm}$, and the film thickness of the $\mathrm{n}$ region and $\mathrm{Al}$ region used in the silicon solar cells were also the same. Fig. 7(b) illustrates the absorption spectra of the silicon nanopillar solar cell with the absorption for different high aspect ratios $(h / d=1: 2,3: 4,1: 1,3: 2,2: 1,5: 2$, and $3: 1$ ) of nanopillar arrays. The periodicity of the nanopillar arrays was $50 \mathrm{~nm}$. As observed in Fig. 6(b), in this structure, the average absorption of $h / d=2: 1$ with the wavelength range of $300-700 \mathrm{~nm}$ based on the silicon nanopillar cell was $24.64 \%$, while the average absorptions for $h / d=1: 2,3: 4,1: 1,3: 2$, $5: 2$, and $3: 1$ were $14.31 \%, 17.56 \%, 20.28 \%, 23.34 \%, 22.80 \%$, and $23.72 \%$, respectively. As inspected, the light absorption for all the $h / d=1: 2,3: 4,1: 1,3: 2,5: 2$, and $3: 1$ was less than that of light $h / d=2: 1$ in this light absorption structure. Moreover, to obtain the optimal light trapping structure for the silicon nanopillar solar cell, we also investigated the effect of periodicity for the nanopillar arrays on the absorption efficiency. The high aspect ratio $(h / d=2: 1)$ of nanopillar arrays was applied. Fig. 7 (c) illustrates the absorption spectra of the silicon nanopillar solar cell with the absorption for different periodicities $(P=5,10,15,20,30,40$, and $50 \mathrm{~nm})$ of the nanopillar arrays. As observed in the Fig. $7(\mathrm{c})$, the average absorption for $P=20 \mathrm{~nm}$ with the wavelength range of 300$700 \mathrm{~nm}$ based on the silicon nanowire cell was $29.32 \%$, while the average absorptions for $P=5,10,15,30,40$, and $50 \mathrm{~nm}$ were $18.21 \%, 22.68 \%, 29.17 \%, 28.76 \%, 28.08 \%$, and $24.64 \%$, respectively. As inspected, the light absorption for all $P=5,10$, $15,30,40$, and $50 \mathrm{~nm}$ was less than that of light $P=20 \mathrm{~nm}$ in this light absorption structure. As a result, to absorb the incident light, with the increased high aspect ratio or periodicity, the absorption efficiency increase first and then decreases. The maximum average absorption of the nanopillar solar cell was $24.64 \%$, and the high aspect ratio $(h / d)$ and periodicity were $2: 1$ and $50 \mathrm{~nm}$. Fig. $7\left(\mathrm{~b}_{1}-\mathrm{b}_{3}\right)$ present the distribution of electric field intensity for this structure $(h / d=2: 1)$ illustrated with the incident wavelengths of $\lambda=300,455$, and $700 \mathrm{~nm}$, respectively. As shown in Fig. $7\left(b_{1}-b_{3}\right)$, the effect of light trapping for the cells with short incident wavelength was much greater than for the long incident wavelength. Although the absorption peak has a changed response to $410 \mathrm{~nm}$ and $48.5 \%$ of the photons have been absorbed, the absorptive intensity is much less than for the short wavelength of 300 or $350 \mathrm{~nm}$. Furthermore, we also investigated the effect of the periodicity of the nanopillar arrays on the absorption efficiency. Fig. $7\left(c_{1}-c_{5}\right)$ present the distribution of electric field intensity $(P=20 \mathrm{~nm})$ with the incident wavelengths of $\lambda=300,380,390,500$, and $700 \mathrm{~nm}$, respectively. The maximum average absorption of the nanopillar solar cell was $29.32 \%$ with the more closely packed nanopillar arrays. The effect of the distribution of electric field intensity was also apparently less with the increased light wavelength. Finally, the optimal light trapping for the silicon nanopillar solar cell was calculated, and the high aspect ratio, periodicity, and diameter 
(a)
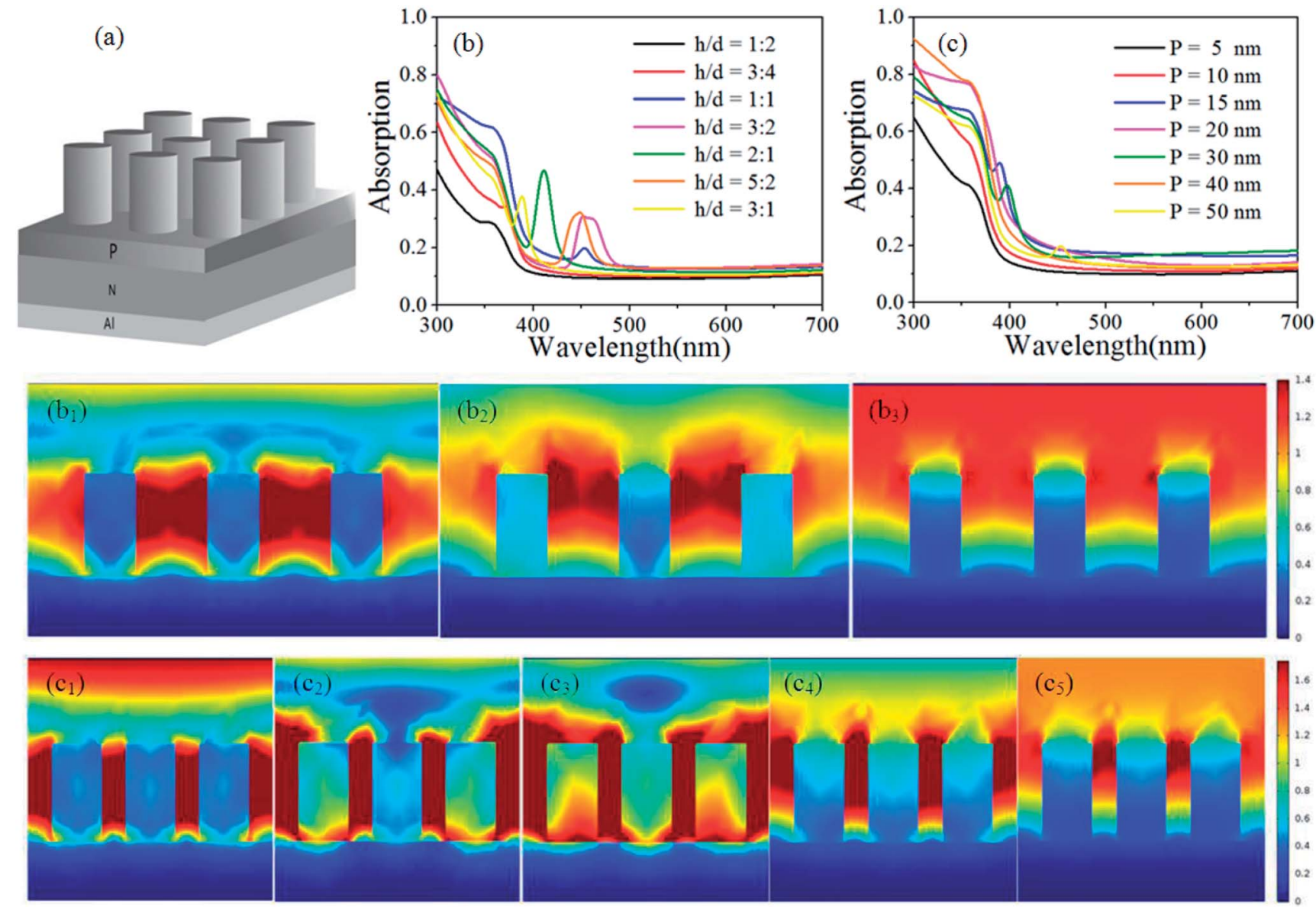

(c)

Fig. 7 (a) Diagram of the silicon nanopillar solar cell; (b) and (c) absorption with the wavelength range of 300-700 nm based on different high aspect ratios or periodicities for silicon nanopillar solar cells. The distribution of electric field intensity for this structure $(h / d=2: 1)$ is also illustrated in $\left(b_{1}-b_{3}\right)$ with the incident wavelengths of $\lambda=300,455$, and $700 \mathrm{~nm}$, respectively. The distribution of electric field intensity for this structure $(P=20 \mathrm{~nm})$ is illustrated in $\left(c_{1}-c_{5}\right)$ with the incident wavelengths $\lambda=300,380,390,500$, and $700 \mathrm{~nm}$.

were $2: 1,20 \mathrm{~nm}$, and $40 \mathrm{~nm}$, respectively. The nanopillar solar cell has the maximum average absorption with $54.64 \%$ photons absorbed with the incident light wavelength of $350 \mathrm{~nm}$.

In addition, Fig. 8(a and b) illustrates the absorption spectra of the silicon nanopillar solar cells with different thicknesses of silicon nitride ( $L=4,9,20,30$, and $40 \mathrm{~nm})$. In Fig. 8(a), the silicon nanopillar solar cell uses a thin silicon nitride coating to passivate the top surface, usually as an antireflection coating. A high aspect ratio $(h / d=2: 1)$ was applied, and the diameter or periodicity were both $40 \mathrm{~nm}$. In this calculation, the simulation based on the incident light was performed vertically. Due to the varying thickness of silicon nitride, using the optimal parameters for the silicon nanopillar solar cells allowed obtaining the best of light absorption. As observed in Fig. 8(b), the average absorptions of the different thicknesses for silicon nitride $(L=$ 4, 9 and $20 \mathrm{~nm}$ ) for the radial pillar solar cell with the light wavelength range $300-700 \mathrm{~nm}$ were $33.72 \%, 35.33 \%$, and $37.32 \%$, while the average absorptions for the thickness of silicon nitride of $L=30$ and $40 \mathrm{~nm}$ were $31.99 \%$ and $30.98 \%$, respectively. As inspected, the light absorption for all the different thicknesses of silicon nitride $(L=4,9,30$, and $40 \mathrm{~nm})$ was less than the light absorption for a thickness of silicon nitride of $L=20 \mathrm{~nm}$ for the nanopillar solar cell. Furthermore,
Fig. 8(b) illustrates the absorption spectra of the silicon nanopillar solar cell structure without silicon nitride. Therefore, by comparing the absorption of the two models, the ability to absorb light of combined model was better than that for the model without an antireflection coating. Fig. $8\left(b_{1}-b_{5}\right)$ illustrate the distribution of electric field intensity for this structure with the different thicknesses of $L=4,9,20,30$, and $40 \mathrm{~nm}$ of silicon nitride with the incident wavelength of $350 \mathrm{~nm}$. As well as the optimal light-trapping structure of the silicon nanopillar solar cell, this structure also causes a strong field enhancement between the silicon nitride and the surface active layer. So the absorption of the surface film of silicon nanopillar solar cell is also enhanced by the antireflection-coating structure.

Panels (a-c) of Fig. 9 show SEM micrographs of silicon nanopillar arrays with different high aspect ratios. As can be seen in Fig. 9(a and b), the surface or cross-sectional SEM images of the nanopillar arrays with the scale of $10 \mu \mathrm{m}$ show that the thickness of the positive photoresist is $971.4 \mathrm{~nm}$, and the diameter of nanopillar is from $4.66 \mu \mathrm{m}$ to $5.10 \mu \mathrm{m}$. In the experiment, the exposed silicon dioxide of the samples was etched in a solution of $\mathrm{NH}_{4} \mathrm{~F}, \mathrm{HF}$, and deionized water with the ratio $6 \mathrm{~g}: 3 \mathrm{ml}: 10 \mathrm{ml}$ for $45 \mathrm{~s}$ at room temperature (see Fig. $\left.1\left(c_{3}\right)\right)$. The edge of silicon dioxide was etched. The edge of 
(a)

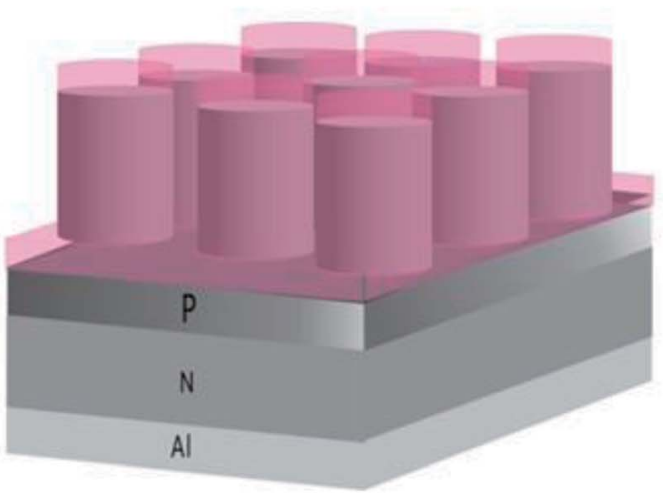

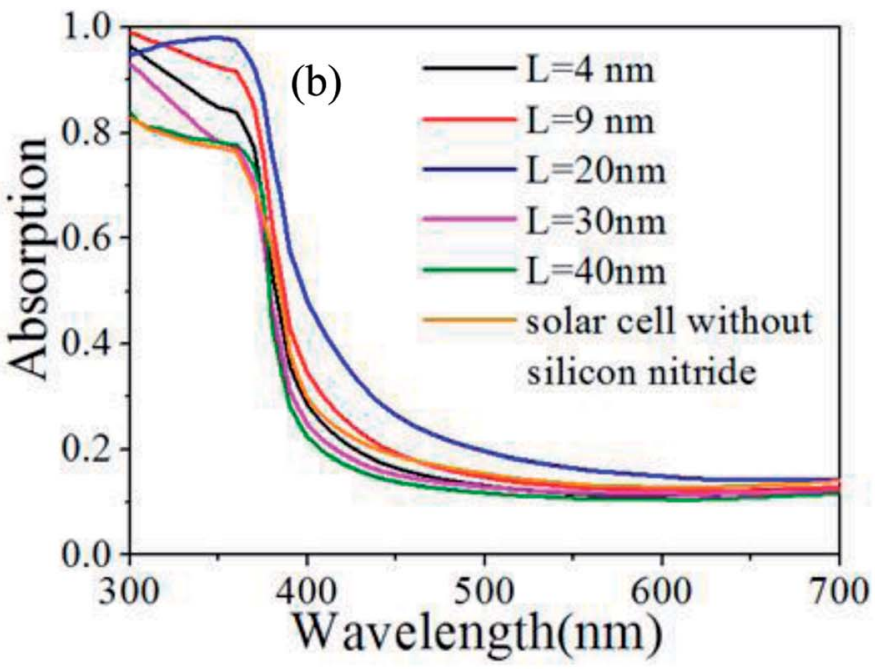
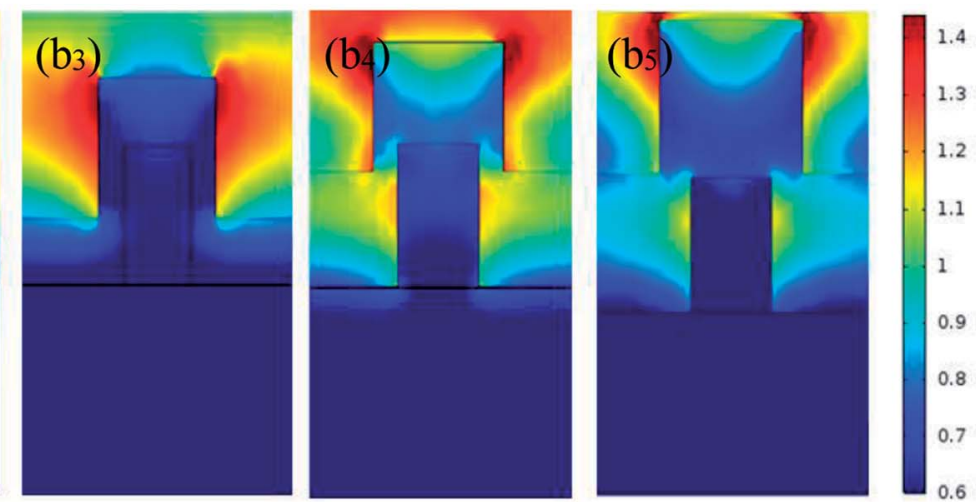

Fig. 8 (a) Diagram of the silicon combined (nanopillar with silicon nitride) solar cell; (b) absorption with the wavelength range of 300-700 nm based on different thicknesses of silicon nitride silicon nanopillar solar cell. The distribution of electric field intensity for this structure with the silicon nitride is also illustrated in $\left(b_{1}-b_{5}\right)$ with the incident wavelength of $\lambda=350 \mathrm{~nm}$.

the $5 \mu \mathrm{m}$ circular pattern positive photoresist point was etched by the plasma of $\mathrm{SF}_{6}$ and $\mathrm{O}_{2}$ with the increasing etching time. Then, the exposed silicon surface without silicon dioxide was etched. As shown in Fig. 9(c), the experimental results show that the morphologies of the silicon nanopillar arrays were deposited on the silicon surface when the circular-shape positive photoresist points were cleaned by the acetone solution. Also, a better shape of nanopillar arrays was obtained with the high aspect ratio $(h / d=2: 1)$. Fig. 9(d) presents the total reflections of the silicon nanopillar solar cells with different high aspect ratios of nanopillar arrays. The average reflections of the high aspect ratios $(h / d=1: 2,3: 2$, and $2: 1)$ for the nanopillar cell in the range of $300-1100 \mathrm{~nm}$ are $27.9 \%, 23.59 \%$, and $17.76 \%$, while the average reflection of the silicon planar was $43.44 \%$. The high aspect ratio $(h / d=2: 1)$ of the silicon nanopillar solar cell with a lower reflectance would trap more incident light.

\subsection{Electrical characteristics of the silicon nanopillar solar cell with silicon nitride}

Fig. 10(a) presents the total reflections of silicon nitride films on the glasses with different deposition times by plasma-enhanced chemical vapor deposition. The average reflection of the deposition times $t=4,6$, and $8 \mathrm{~min}$ for the silicon nitride films in the range of $300-1000 \mathrm{~nm}$ were $21.53 \%, 23.17 \%$, and $26.26 \%$, while the average reflection for the deposition times $t=10,12$, and 14 min were $21.25 \%, 26 \%$, and $30.35 \%$. As inspected, the light reflections of $t=4,6,8,12$, or $14 \mathrm{~min}$ were more than that for $t$ $=10 \mathrm{~min}$ in this film of structures. As a result, to reflect the incident light, with the increase in deposition time, the reflection efficiency is increased first and then decreases, and the film with a deposition time of $t=10 \mathrm{~min}$ had the lowest of reflection. The silicon nanopillar solar cell with a lower reflection would trap incident light more than the higher reflection cells. So the deposition time $t=10 \mathrm{~min}$ of silicon nitride films was applied for the silicon nanopillar solar cell as the antireflection coating. So the silicon nanopillar solar cell with $h / d=2: 1$ and a deposition time of $t=10 \mathrm{~min}$ of silicon nitride films was applied on the combined structure (silicon nanopillar/silicon nitride solar cells). Fig. 10(b) presents the total reflections of the combined structure and an untreated structure. The average reflections of the two kinds of solar cells in the range of 300-1100 nm were $13.77 \%$ and $17.76 \%$. The combined solar cell with a lower reflectance would trap more incident light. 

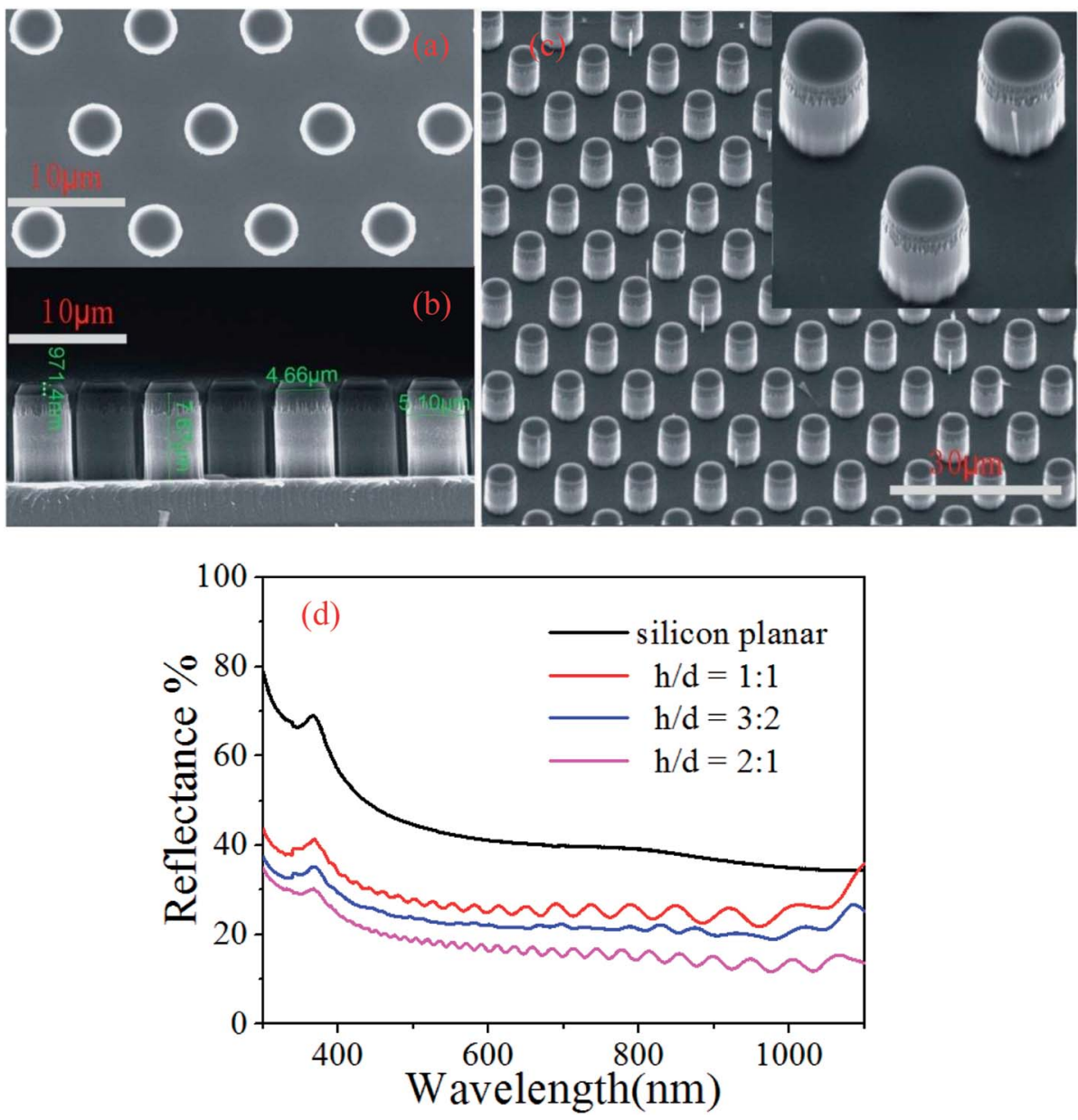

Fig. 9 (a)-(c) SEM micrographs of silicon nanopillar arrays with the different high aspect ratios (d) total reflections of the different high aspect ratios for the silicon nanopillar solar cells.

Four kinds of solar cells based on different structures were measured under AM 1.5G illumination, as shown in the current density-voltage $(J-V)$ characterization in Fig. 11 and Table 1. Table 1 shows the results of the $J-V$ measurements of silicon planar, nanocone, nanopillar, and combined solar cells under the standard test conditions. The three kinds of solar cells with a lower reflection trap the incident light more than the higher reflection of cells. Therefore, the etching time $t=30 \mathrm{~min}$ for the silicon nanowire solar cell, the ICP etching time $t=3 \mathrm{~min}$ for the silicon nanocone solar cell, and the high aspect ratio $h / d=$ 2 : 1 were applied.

The power conversion efficiency of the solar cell is $\eta$ :
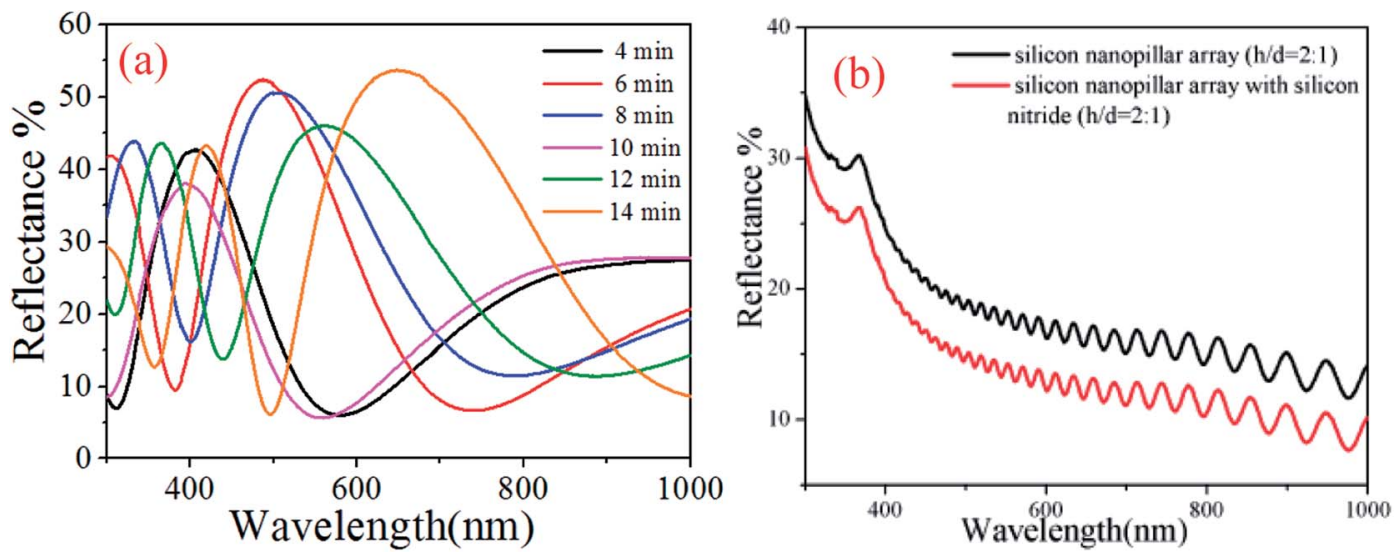

Fig. 10 (a) Total reflections of the different depositing times for the silicon nitride films. (b) Total reflections of the silicon nanopillar/silicon nitride solar cells and of the untreated structure. 


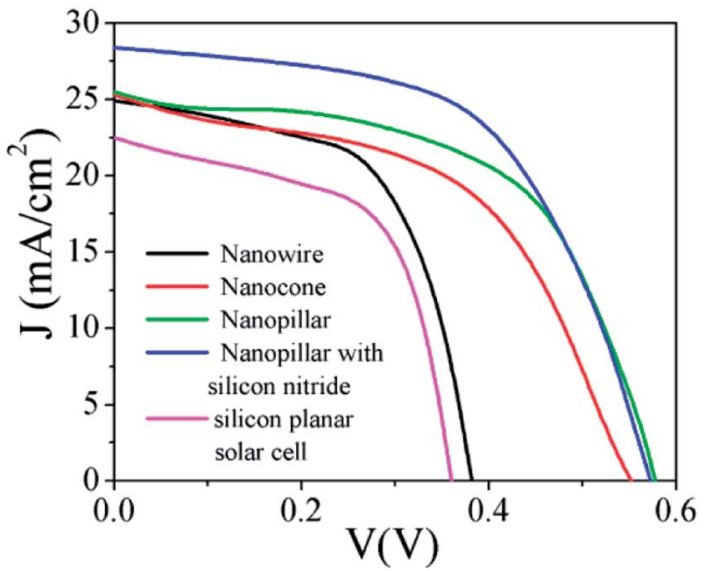

Fig. $11 J-V$ characteristics of four kinds of silicon (planar, nanowire, nanocone, nanopillar) heterojunction solar cell.

$$
\eta=\frac{I_{\mathrm{SC}} V_{\mathrm{OC}} \mathrm{FF}}{P_{\text {in }}}
$$

where $I_{\mathrm{SC}}$ is the short-circuit current, $V_{\mathrm{OC}}$ is the open-circuit voltage, and FF is the fill factor. In our experiment, all the solar cells based on the different structures were measured under AM 1.5G illumination. Therefore, the $P_{\text {in }}$ was $100 \mathrm{~mW}$ $\mathrm{cm}^{-2}$. Eqn (3) shows that the short-circuit current $I_{\mathrm{SC}}$, the opencircuit voltage $V_{\mathrm{OC}}$, and the fill factor $\mathrm{FF}$ are the main factors that affect the PCE $\eta$. The value of $I_{\mathrm{SC}}=\frac{J_{\mathrm{SC}}}{S}$ is related to the light absorption and carrier collection.

The maximum current density $J_{\mathrm{SC}}$ of the four kinds of cells appears in nanopillars/( $h / d=2: 1)$, in which the mean value of $J_{\mathrm{SC}}$ was higher than for planar, nanowires/30 min or nanocones/ $3 \mathrm{~min}$ by $3,0.6$, and $0.2 \mathrm{~mA} \mathrm{~cm}^{-2}$. But the mean value of $J_{\mathrm{SC}}$ for nanopillars with silicon nitride is higher than for nanopillars/ ( $h / d=2: 1$ ) by $3.3 \mathrm{~mA} \mathrm{~cm} \mathrm{~cm}^{-2}$ and more than for planar and nanowires/30 $\mathrm{min}$ or nanocones/3 $\mathrm{min}$ by $6.3,3.9$, and $3.5 \mathrm{~mA}$ $\mathrm{cm}^{-2}$. Moreover, it could be observed that the PCE values of the silicon wires/nanocones/pillars solar cell were $5.76 \%, 7.62 \%$, and $8.40 \%$, while that of the silicon planar solar cell was $5.02 \%$. Thus, there was a significant increase in the photovoltaic performance from such nanostructures to the planar structure.

In addition, it could be observed that the $J_{\mathrm{SC}}$ of the solar cell with the nanopillar $/(h / d=2: 1)$ was $25.5 \mathrm{~mA} \mathrm{~cm}^{-2}$, while that of the combined structure with (nanopillar with silicon nitride) was $28.8 \mathrm{~mA} \mathrm{~cm}^{-2}$. Thus, there was a significant increase for light wavelengths from the combined solar cell to the untreated structure. On the other hand, the performance of the combined solar cell was better than that of the untreated solar cell. This was in accordance with the markedly higher light absorbed and lower reflection by the structure, as shown in Fig. 8(a) and 10(a). It can be seen that the combined structure (nanopillar with silicon nitride) exhibited a PCE of $9.4 \%\left(J_{\mathrm{SC}}=28.8 \mathrm{~mA} \mathrm{~cm}{ }^{-2}\right.$, $\left.V_{\mathrm{OC}}=574 \mathrm{mV}, \mathrm{FF}=58 \%\right)$. In contrast, one fabricated on the untreated structure (nanopillar $/ h / d=2: 1$ ) had a PCE of $8.4 \%$ $\left(J_{\mathrm{SC}}=25.5 \mathrm{~mA} \mathrm{~cm}^{-2}, V_{\mathrm{OC}}=580 \mathrm{mV}, \mathrm{FF}=57 \%\right)$. The properties of trapping light for silicon nitride films have a prominent impact on the improvement of the power conversion efficiency for the hybrid solar cells. Also, the nanowire and nanocone structures exhibited a lower PCE of $5.76 \%\left(J_{\mathrm{SC}}=24.9 \mathrm{~mA} \mathrm{~cm}^{-2}\right.$, $\left.V_{\mathrm{OC}}=382 \mathrm{mV}, \mathrm{FF}=60 \%\right)$ and $7.62 \%\left(J_{\mathrm{SC}}=25.3 \mathrm{~mA} \mathrm{~cm}^{-2}, V_{\mathrm{OC}}\right.$ $=544 \mathrm{mV}, \mathrm{FF}=55 \%$ ). Compared to the silicon nanowire or nanocone solar cells, the light trapping of the silicon nanopillar solar cell is low, although the performance is not disappointing. Also, the PCE of nanopillar/( $h / d=2: 1)$ was enhanced by $31 \%$, while the PCE of combined structure (nanopillar with silicon nitride) was enhanced by $38 \%$, in contrast to the silicon nanowire solar cell, as shown in the set of Table 1 . Although the structure with the nanowire/30 $\mathrm{min}$ and nanocone $/ 3 \mathrm{~min}$ exhibited a better light trapping ability, both the mean values of $\mathrm{FF}$ and $V_{\mathrm{OC}}$ of the solar cells were similar and lower than that of the cell based on the antireflection coating, as shown in Table 1.

\section{Conclusion}

In this paper, we introduced the ICP method for preparing two kinds of silicon solar cell arrays: silicon nanocones and silicon nanopillars. Moreover, silicon nanowire arrays were also prepared by a Ag-assisted chemical etching method. We simulated the performance of the silicon planar, nanowire, nanocone, nanopillar, and combined solar cells with the absorption of light for different heights or periodicities of arrays. The optimal percents of light absorption for the silicon wires/ nanocones/pillars/combined solar cells were $24.02 \%, 42.49 \%$, $29.32 \%$, and $37.32 \%$, respectively. By comparing the absorption and the optimal electric field intensity distribution of the combined structure and untreated structure, the ability to absorb light of the combined model was better than the untreated structure. Finally, we experimentally demonstrated the current density-voltage characterization of the four structures. The PCE of the solar cell based on the combined structure was better than that of the nanopillar array. As for the antireflection coating films, silicon nitride was applied for the silicon nanopillar solar cell, and a PCE of 9.4\% for the combined solar cell was obtained. This had a prominent impact on the improvement of PCE for silicon nanopillar solar cells.

Table 1 Photovoltaic properties of the hybrid Si planar, nanowire, nanocone, or nanopillar solar cells

\begin{tabular}{lllrl}
\hline & $J_{\text {SC }}\left(\mathrm{mA} \mathrm{cm}^{-2}\right)$ & $V_{\text {OC }}(\mathrm{V})$ & FF $(\%)$ & PCE $(\%)$ \\
\hline Si planar solar cell & 22.5 & 0.360 & 62 & 5.02 \\
Nanowire/30 min & 24.9 & 0.382 & 60 & 5.76 \\
Nanocone/3 min & 25.3 & 0.544 & 55 & 7.62 \\
Nanopillar/(h/d=2:1) & 25.5 & 0.580 & 57 & 5.40 \\
Nanopillar with silicon nitride & 28.8 & 0.574 & 58 & 9.40
\end{tabular}




\section{Conflicts of interest}

There are no conflicts to declare.

\section{References}

1 J. C. Jimeno, V. Rodríguez, R. Gutiérrez, F. Recart, G. Bueno and F. Hernando, 16th Eur. Photovoltaic Sol. Energy Conf., 2000, vol. 5, pp. 1-5.

2 K. S. Do, T. H. Baek, M. G. Kang, S. J. Choi, G. H. Kang, G. J. Yu, J. C. Lee, J. M. Myoung and H. E. Song, Met. Mater. Int., 2014, 20, 545-550.

3 X. Li, Y. Xiao, K. Zhou, J. Wang, S. L. Schweizer, A. Sprafke, J.-H. Lee and R. B. Wehrspohn, Phys. Chem. Chem. Phys., 2015, 17, 800-804.

4 S. Y. Zhang, W. Liu, Z. F. Li, M. Liu, Y. S. Liu, X. D. Wang and F. H. Yang, Chin. Phys. B, 2016, 25, 106802.

5 L. H. Niu, X. H. Jiang, Y. L. Zhao, H. G. Ma, J. J. Yang, K. Cheng and Z. L. Du, Nanotechnology, 2016, 27, 315601.

6 Z. Fan, W. Zhang, Y. Fu, L. Yan and X. Ma, J. Phys. Chem. C, 2016, 120, 6824-6834.

7 Y. He, J. Quan and G. Ouyang, Phys. Chem. Chem. Phys., 2016, 18, 7001-7006.

8 Y. P. Xing, K. L. Zhang, J. S. Zhao, P. D. Han, Z. C. Yang, Y. J. Yuan and Q. Ding, Optik, 2017, 128, 133-138.

9 D. R. Kim, C. H. Lee, P. M. Rao, I. S. Cho and X. Zheng, Nano Lett., 2011, 11, 2704-2708.

10 B. Dou, R. Jia, H. Li, C. Chen, W. Ding, Y. Meng, Z. Xing, X. Liu and T. Ye, Appl. Phys. Lett., 2012, $101(18), 183901$.

11 J. Shieh, Y. C. Li, C. Y. Ji, C. C. Chiu and H. Y. Lin, J. Renewable Sustainable Energy, 2015, 7, 033102.

12 J. Zhu, Z. F. Yu, G. F. Burkhard, C. M. Hsu, S. T. Connor, Y. Q. Xu, Q. Wang, M. McGehee, S. H. Fan and Y. Cui, Nano Lett., 2009, 9, 279-282.

13 H. F. Li, R. Jia, C. Chen, Z. Xing, W. C. Ding, Y. L. Meng, D. Q. Wu, X. Y. Liu and T. C. Ye, Appl. Phys. Lett., 2011, 98, 151116.

14 M. D. Kelzenberg, S. W. Boettcher, J. A. Petykiewicz, D. B. Turner-Evans, M. C. Putnam, E. L. Warren, J. M. Spurgeon, R. M. Briggs, N. S. Lewis and H. A. Atwater, Nat. Mater., 2010, 9, 239-244.

15 G. Andra, M. Pietsch, T. Stelzner, A. Gawlik, E. Ose, S. Christiansen, F. Falk and IEEE, in Pvsc: 2008 33rd IEEE Photovoltaic Spec. Conf., 2008, vol. 1-4, pp. 118-121.

16 A. Surawijaya, I. Anshori, A. Rohiman and I. Idris, 4th Nanosci. Nanotechnol. Symposi., ed. F. Iskandar, Khairurrijal and M. Abdullah, 2011, p. 1415.

17 M. F. Hainey and J. M. Redwing, Appl. Phys. Rev., 2016, 3, 040806.

18 H. Fang, Y. Wu, J. H. Zhao and J. Zhu, Nanotechnology, 2006, 17, 3768-3774.

19 M.-L. Zhang, K.-Q. Peng, X. Fan, J.-S. Jie, R.-Q. Zhang, S.-T. Lee and N.-B. Wong, J. Phys. Chem. C, 2008, 112, 4444-4450.

20 K. Q. Peng, J. J. Hu, Y. J. Yan, Y. Wu, H. Fang, Y. Xu, S. T. Lee and J. Zhu, Adv. Funct. Mater., 2006, 16, 387-394.
21 K. Pal, U. N. Maiti, T. P. Majumder, P. Dash, N. C. Mishra, N. Bennis and J. M. Otón, J. Mol. Liq., 2011, 164, 233-238.

22 S. Sagadevan, K. Pal and Z. Z. Chowdhury, J. Mater. Sci.: Mater. Electron., 2017, 28(22), 17193-17201.

23 K. Pal, T. P. Majumder, C. Neogy and S. C. Debnath, J. Mol. Struct., 2012, 1016, 30-38.

24 H. J. Syu, S. C. Shiu and C. F. Lin, Sol. Energy Mater. Sol. Cells, 2012, 98, 267-272.

25 Z. W. Zuo, K. Zhu, G. L. Cui, W. X. Huang, J. Qu, Y. Shi, Y. S. Liu and G. B. Ji, Sol. Energy Mater. Sol. Cells, 2014, 125, 248-252.

26 A. Najar, A. B. Slimane, M. N. Hedhili, D. Anjum, R. Sougrat, T. K. Ng and B. S. Ooi, J. Appl. Phys., 2012, 112, 033502.

27 H. Chen, Q. Zhang and S. Y. Chou, Nanotechnology, 2015, 26, 085302.

28 J. Liu, X. S. Zhang, G. J. Sun, Y. T. Wang, B. Wang, T. C. Zhang, F. T. Yi and F. Chen, Energy Technol., 2016, 4, 298-303.

29 J. Liu, Y. X. Liao, B. Wang and F. T. Yi, Sol. Energy, 2011, 694, 375-379.

30 A. Pateau, A. Rhallabi, M. C. Fernandez, M. Boufnichel and F. Roqueta, J. Vac. Sci. Technol., A, 2014, 32(2), 021303.

31 S. C. Chen, Y. C. Lin, J. C. Wu, L. Horng and C. H. Cheng, Microsyst. Technol., 2007, 13, 465-474.

32 H. Tosaka US Pat. Appl., A1[P], US20080299777, 2008.

33 E. Garnett and P. Yang, Nano Lett., 2010, 10, 1082-1087.

34 L. S. Golobokova, Y. V. Nastaushev, F. N. Dultsev, D. V. Gulyaev, A. B. Talochkin and A. V. Latyshev, in Iop 1st Inter. Sch. Conf., S-Peters, 2014, p. 541.

35 L. Tsakalakos, J. Balch, J. Fronheiser, B. A. Korevaar, O. Sulima and J. Rand, Appl. Phys. Lett., 2007, 91, 233117.

36 L. Tsakalakos, J. Balch, J. Fronheiser, M. Y. Shih, S. F. LeBoeuf, M. Pietrzykowski, P. J. Codella, O. Sulima, J. Rand, A. D. Kumar, B. A. Korevaar and IEEE, W. Conf. on Photovol. Energy Conf., 2006, pp. 111-113.

37 L. Hu and G. Chen, Nano Lett., 2007, 7, 3249-3252.

38 Q. T. Li, Z. C. Ni, S. M. Yang, J. L. Gong, D. Z. Zhu and Z. Y. Zhu, Nucl. Instrum. Methods Phys. Res., 2008, 266, 197-202.

39 X. M. Meng, N. G. Shang, C. S. Lee, I. Bello and S. T. Lee, Phys. Status Solidi A, 2005, 202, 2479-2483.

40 K. C. Sahoo, M. K. Lin, E. Y. Chang, T. B. Tinh, Y. M. Li and J. H. Huang, Jpn. J. Appl. Phys., 2009, 48, 126508.

41 H. P. Wang, K. Y. Lai, Y. R. Lin, C. A. Lin and J. H. He, Langmuir, 2010, 26, 12855-12858.

42 P. F. Liu, P. Gemeiner, H. Shen, X. J. Meng, J. H. Chu, S. Geiger, N. Guiblin and B. Dkhil, J. Appl. Phys., 2009, 106, 054111.

43 G. Conibeer, M. Green, R. Corkish, Y. Cho, E. C. Cho, C. W. Jiang, T. Fangsuwannarak, E. Pink, Y. Huang, T. Puzzer, T. Trupke, B. Richards, A. Shalav and K. L. Lin, Thin Solid Films, 2006, 511-512, 654-662.

44 J. S. Li, H. Y. Yu, S. M. Wong, G. Zhang, X. W. Sun, P. G. Q. Lo and D. L. Kwong, Appl. Phys. Lett., 2009, 95, 255101.

45 H. Shen, P. Bienstman and B. Maes, J. Appl. Phys., 2009, 106, 073109. 
46 Y.-K. Jia, E. Yang Shi, Q.-N. Guo, Y.-S. Chen, X.-Y. Gao, J.-H. Gu and J.-X. Lu, Acta Phys. Sin., 2013, 62, 247801.

47 F. Shan, T. Zhang and S.-Q. Zhu, J. Nanomater., 2014, 827658.
48 X. Li, N. P. Hylton, V. Giannini, K.-H. Lee, N. J. Ekins-Daukes and S. A. Maier, Opt. Express, 2011, 19, A888-A896. 